\title{
Boring a Discontinuous Surface: the Choice of Technological Modes
}

\author{
Alexander Firsov ${ }^{1}$, Alexander Qvcharenko ${ }^{1}$, Alexander Romashev ${ }^{1}$ Vitaly Smirnov ${ }^{1}$, and \\ Aleksey Kamardin ${ }^{2}$ \\ ${ }^{1}$ Biysk Technological Institute (branch) of the Altay State Technical University, 659305, Hero of the \\ Soviet Union Trofimov Street, 27, Biysk, Altai region, Russian Federation
}

${ }^{2}$ Scientific and technical center of the Science Academy of the Republic of Uzbekistan, $70 \mathrm{~J}$.

Gulomova Street, Tashkent, 100047, Uzbekistan

\begin{abstract}
The article deals with issues related to ensuring the quality of machining of a discontinuous surface. The subject of research is the technology of boring holes. Machining holes with intermittent areas on the surface is difficult due to the occurrence of dynamic effects. As a rule, regulatory and technical documentation does not give specific recommendations for such cases. The authors of the article describe the introduction of additional conditions, which allow determining the modes of boring holes with intermittent areas on the surface at the design stage of the technological process. This solution ensures that the part meets the specified quality requirements and allows you to verify the correctness of the technological decisions. The algorithm for selecting boring modes of holes with discontinuous surfaces implements the proposed technical solution in practice.
\end{abstract}

\section{Introduction}

In the practice of machining products that have intermittent surfaces are often found. At the same time, technical requirements for these surfaces are quite stringent. This refers to the roughness, accuracy of shape and size specified for the cylinder bores of engines, hydraulic and pneumatic cylinders, distribution equipment, etc. Intersecting holes or windows are usually characteristic structural elements for a given type of the part. When designing technological operations for processing such holes on boring machines, difficulties arise as the regulatory and technical documentation does not provide for the issuance of specific recommendations on the choice of processing conditions for discontinuous surfaces. The technologist is forced to adjust the developed technological process, which leads to an increase in the timing of the finished product. The situation described makes relevant research aimed at the development of special technical solutions. Such solutions should allow, at the stage of technological preparation of production already, to check the performance of the details of the technical requirements indicated on the drawing and thus to reduce the time of development and debugging of the technological process.

Well-known researchers were engaged in solving the problems of processing quality of discontinuous surfaces. A number of experiments on the study of intermittent cutting and 
evaluation of the cutting tool performance were described in the works of several authors [1-5]. The issues of ensuring the quality of the processed surface with intermittent turning by cutting tools made of composite material are considered in [6,7]. In [8, 9], optimization and improvement of machining of parts with intermittent surfaces are discussed, and methods for machining discontinuous surfaces by boring aimed at eliminating the negative impact of the pulse-impulse load on the tool tip are proposed. The studies described by the authors in papers [10-13] are devoted to the behavior of various grades of structural and tool material under conditions of intermittent cutting. A number of practical recommendations for the implementation of intermittent cutting gives Metal cutting Technical Guide from the company Sandvik Coromant. However, many issues of theoretical and practical sense remain unresolved.

\section{Description of research}

We consider the machining of the base hole of the basic part. This hole has a discontinuous surface in the form of a window with the length 1 (Figure 1a). The penetration of the tool into the window edge is accompanied by the appearance of forced oscillations, depending on the amplitude and frequency which may cause deterioration of the surface roughness, appearance of waviness or deviations of the shape of the hole. The dynamic impact of a discontinuous surface on the tool can cause chipping of the cutting edge of the tool. Thus, the presence of a discontinuous cylindrical surface in the form of windows, grooves or intersecting holes leads to the appearance of failures, which characterize the deterioration of the quality parameters of the base hole and decrease in the durability of the cutting tool.

We will eliminate the identified failures using the inter-branch fund of the heuristic techniques given in [14]. The results of research to eliminate the failures detected are presented in Table 1. To prevent failures caused by discontinuity of the treated surface, we suggest using technological solutions: TS1, TS2, TS3.

Table 1. Variants of technological solutions obtained with the fund of heuristic methods.

\begin{tabular}{|c|c|c|}
\hline Types of failure & Heuristic method & Technological solutions \\
\hline $\begin{array}{l}\text { 1. The deterioration of } \\
\text { roughness or the appearance } \\
\text { of waviness in the } \\
\text { processing of discontinuous } \\
\text { surfaces } \\
\text { 2. Chipping of the cutting } \\
\text { edge during processing of a } \\
\text { discontinuous surface with } \\
\text { windows (reduced } \\
\text { performance) }\end{array}$ & $\begin{array}{l}\text { Ensuring the reduction or } \\
\text { elimination of vibration, } \\
\text { shock loads }\end{array}$ & $\begin{array}{l}\text { TS1 - Selection of } \\
\text { processing modes that } \\
\text { reduce shock loads } \\
\text { TS2 - Filling a window } \\
\text { with a material similar in } \\
\text { physical properties to the } \\
\text { material of the workpiece } \\
\text { TS3 - Use tool with } \\
\text { damping element }\end{array}$ \\
\hline
\end{tabular}

TS1 provides a choice of cutting conditions that reduce impact loads. This decision is due to the following phenomenon occurring when machining a hole with a diameter $D$ (Fig. 1a), with a window size $l$, with a boring bar with diameter $d$ and length $L_{\mathrm{i}}$. The mandrel is affected by the radial force $P_{\mathrm{y}}$, which deforms the mandrel by the value of $y$. When passing the window the cutting tool falls into the window being influenced by resilience, and the cutting depth at the moment of cutting into the edge of the window increases by the value $y$ and becomes equal to $t+y$. As far as during the "falling" of the tool into the window, the tool $S$ is being fed, then at the time of plunging it will move by $\Delta S=S \cdot l /(\pi \cdot D)$ (Fig.lb). 


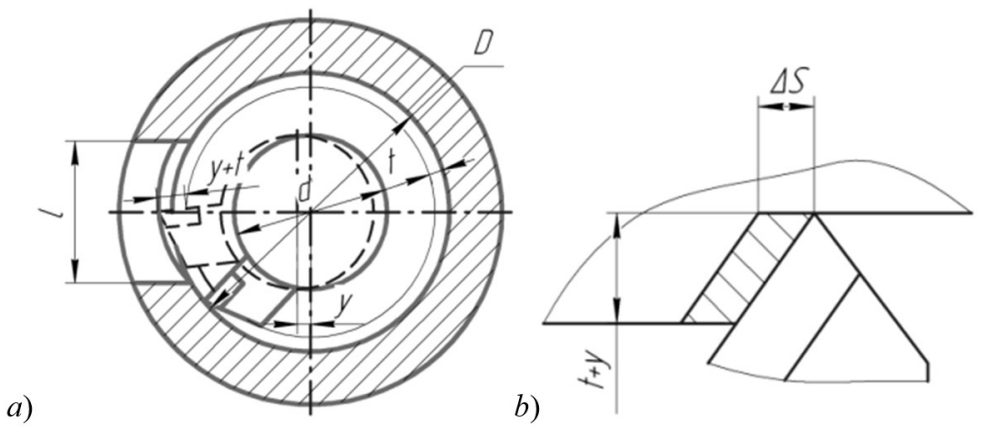

Fig. 1. Schematic representation of the treatment of a discontinuous surface boring: a - changing the position of the cutting tool; $b$ - cutting depth increase at the moment of cutting into the edge of the window.

At the moment of cutting into the edge of the window, the impacting force acts on the cutting tool. If the cutting wedge is not sufficiently strong, then chipping of the cutting edge occurs. Also, under the influence of dynamic force, forced oscillations arise, which may cause resonance and, as a result, deviations of form, waviness and an increased roughness may appear. These phenomena occur when boring holes with discontinuous surfaces require taking into account additional data on the limitations imposed on the choice of cutting modes such as cutting depth $(t)$, feed $(S)$, cutting speed $(V)$. The corresponding set of design data should be expanded to include information on the strength of the cutting wedge, on the tool's stability to the occurrence of resonance, on permissible shape deviations, as well as on permissible waviness and surface roughness.

The strength of the cutting wedge depends on the mechanical properties of the material of the cutting part and the force acting on the wedge. According to the experimental data, the cleavage of the cutting wedge during microfractures occurs within the contact of the tool with the chips, namely, at a distance equal to the width of the plastic deformation area $C$ [3] (Fig. 2a). If we assume that the cutting force $P_{\mathrm{z}}$ is distributed evenly on the cutting edge, then the strength condition applies to the stress $\sigma$ arising in the tool wedge:

$$
\sigma=k \cdot P_{\mathrm{z}} \cdot C / W_{\mathrm{x}} \leq[\sigma],
$$

where $k$ is the dynamic factor; $W_{\mathrm{x}}$ is the moment of the cross section resistance at which chipping will occur; $\sigma$ - the limit of the bending strength of the tool material.

The dynamic coefficient is determined by the formula [15]:

$$
k=1+\left(V_{0}^{2} \cdot j /\left(P_{z} \cdot g\right)\right)^{1 / 2},
$$

where $V_{0}$ is the speed of movement of the striking body; $j$ is the stiffness of the impact body (in our case, the holder of the boring tool); $g$ - gravitational acceleration.

If we determine the cutting force $P_{\mathrm{z}}$ according to the simplified formula [16], then the condition for determining the amount of advance at which the tool does not split, will look like:

$$
S \leq[\sigma] \cdot \pi \cdot D \cdot t \cdot \sin \beta /\left(6 \cdot k \cdot K_{\mathrm{c}} \cdot \sigma \cdot l\right),
$$

where $K_{\mathrm{c}}$ - cutting coefficient, for carbon structural steels $K_{\mathrm{c}} \approx 2.5 ; \sigma-$ ultimate strength of the material processed; $\beta$ is the angle of tapering of the cutting wedge.

When plunging into the edge of the window, the cutting force increases, therefore, the tool is additionally deformed by the value of $y_{1}$ (Fig. $2 b$ ). This will lead to the formation of 
deformation waves, the amplitude of which may exceed the permissible waviness $W$ or roughness $R z$. In the first period of oscillation, the amplitude is $y+y_{1}$. Therefore, the restriction on permissible deformations will take the form

$$
y+y_{1}=\left(L_{\mathrm{i}}^{3} / 3 \cdot E \cdot I\right) \cdot\left(P_{\mathrm{y}}+P_{\mathrm{yt}}\right) \leq(W, R z),
$$

where $P_{\mathrm{yt}}$ is the cutting force $\mathrm{P} y$, acting when the tool is inserted into the edge of the window; $E$ - Young's modulus; $I$ - inertia moment for section.

Condition (4) allows not only to determine the processing modes, based on the permissible value of waviness, roughness, but conduct a verification calculation as well.

a)

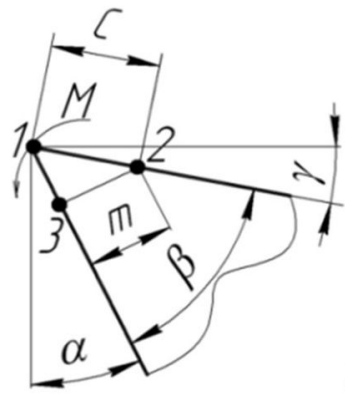

b)

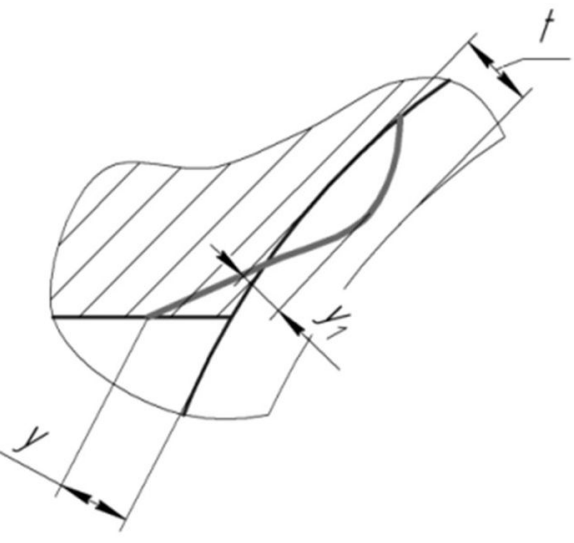

Fig. 2. Scheme to the formulas (1-4): a - cutting wedge, b - formation of deformation waves.

The most unfavorable are the cutting conditions at resonance, which occurs when the ratio of the forced frequency $\omega$ to the natural frequency of oscillations of the system (body) elements $\omega$ is $0.7 \ldots 1.3$ [17]. We assume that: a) the tool's weakest link is the tool holder, b) a tool with rigidity $j$ has one degree of freedom, c) the tool mass $(m)$ is concentrated at the point, $\mathrm{d}$ ) the oscillations are harmonic. Then the circular oscillation frequency is determined by the formula:a

$$
\omega=(\mathrm{j} / \mathrm{m})^{1 / 2}=\left(3 \cdot E \cdot I /\left(L_{\mathrm{i}}^{3} \cdot m\right)\right)^{1 / 2} .
$$

The formula for determining the frequency of forced oscillations is: $\omega_{\mathfrak{b}}=\pi \cdot n \cdot k / 30$, where $n$ is the frequency of rotation of the workpiece; $k$ - the number of interrupting elements.

Thus, the condition of the absence of resonance we write in the form:

$$
0.7 \leq \pi \cdot n \cdot k / 30 /\left(3 \cdot E \cdot I / L_{\mathrm{i}}^{3} m\right)^{1 / 2} \leq 1.3
$$

If there is a probability of resonance, then the technologist has the ability to change the frequency of the disturbing force $\omega$ in the following ways: changing the spindle speed of the machine, reducing the cutting force of $\mathrm{P}_{\mathrm{y}}$, increasing the rigidity of the tool.

Filling windows with material similar in physical properties with structural material (TP2) to reduce the dynamic impact on the cutting tool wedge is advisable in cases where it is economically sound.

To reduce the dynamic impact on the cutting wedge TP 3 involves the use of a tool with a damping device. A scheme of such a tool is shown in Fig. 3; the figures on this scheme indicate: boring tool (1); cutting element (2) located on a supporting surface inclined at an angle $\alpha$; resilient member (3). 


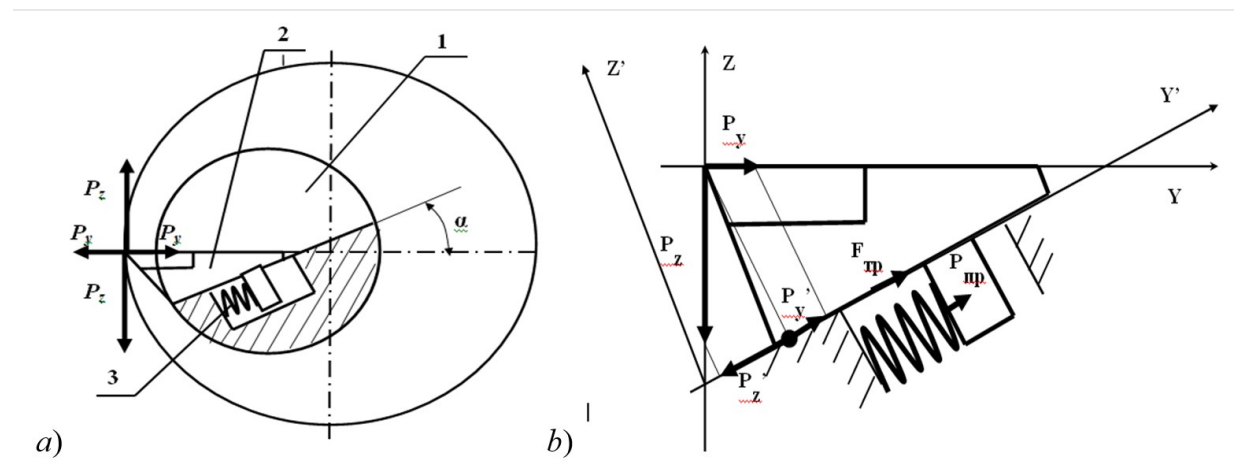

Fig. 3. Scheme to the formulas (1-4): a - cutting wedge, $b$ - formation of deformation waves.

Spring-loaded cutting element 2 (Fig. $3 a$ ) allows to reduce the dynamic impact by compensating for the resilience of the tool and the workpiece that occur during processing. The desired effect is achieved by displacing the cutting element in the opposite direction with the passage of a window by an amount equal to the resilience. Also, this tool has the property of self-tuning when processing workpieces with variable allowance. This effect is due to the fact that an increase in the cutting depth with a variable allowance is accompanied by an increase in cutting forces. The resilience of the tool and the workpiece increases respectively. At the same time, the cutting element is displaced on an inclined surface in the opposite direction, which ensures that the shaping edge of the tool remains unchanged relative to the workpiece. Thus, the task of ensuring the accuracy of the shape of the hole when processing workpieces with variable allowance is solved.

\section{Results and discussion}

On the basis of the obtained additional conditions written in the form of inequalities (3), (4), (6), we present an algorithmic model for designing boring modes for holes with intermittent surfaces. The block diagram of the algorithm is shown in Fig. 4. The initial data of the model in addition to the main limitations include the bending strength of the material of the cutting part of the tool, permissible roughness, waviness or shape deviation in cross section. Calculation of cutting conditions are performed by a technologist on the basis of recommendations from the regulatory and technical documentation. At the same time, he will determine the necessary parameters $\left(P_{\mathrm{y}}, P_{\mathrm{z}}, S, y, y_{1}, k, \sigma, \omega, \omega_{\mathrm{b}}\right)$ to check additional conditions relating to the strength of the cutting edge of the tool, the possibility of resonance, compliance with requirements for roughness, waviness or shape deviations. If at least one condition is not met, the algorithm corrects the feed $\mathrm{S}$ downwards by a certain amount $\Delta S$. The calculation is repeated until all processing conditions are met. In the diagram (Fig. 4), the feed rate serves as a controllable parameter of the model, the depth of cut can be similar to this parameter. We can also vary both parameters at once. 


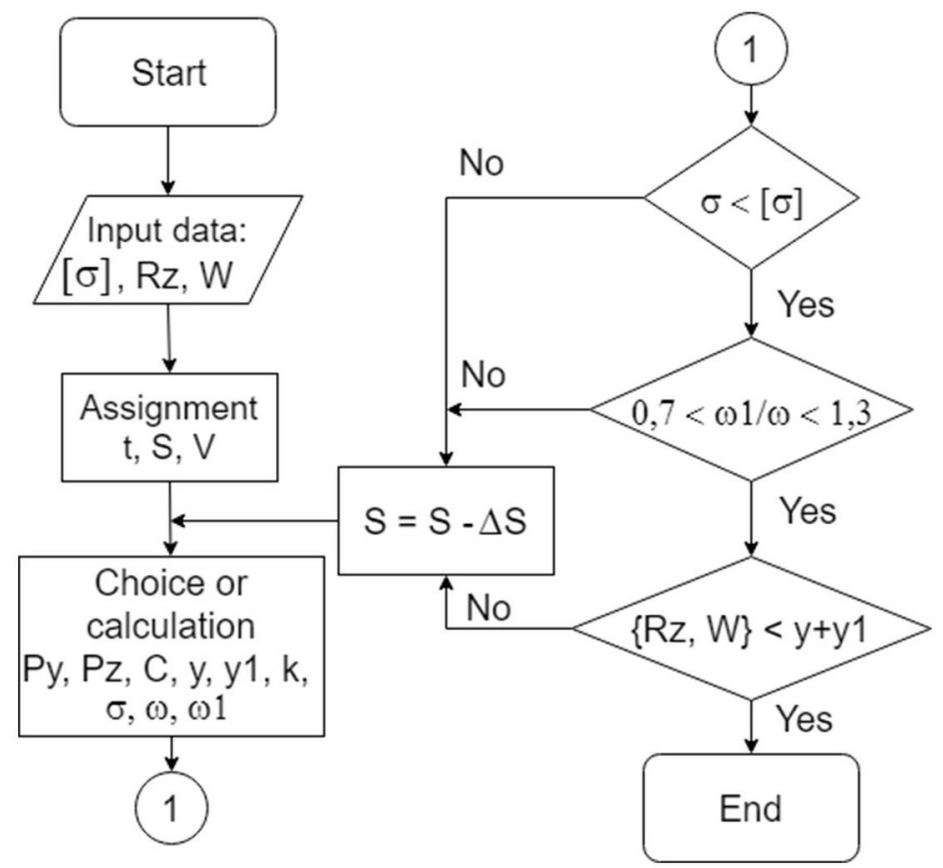

Fig. 4. Block diagram of the algorithm for selecting cutting conditions when machining discontinuous surfaces.

\section{Findings}

1. Products that have holes with discontinuous surfaces in the form of windows, for example, are not technological. When machining such holes by boring, the durability of the cutting tool is reduced, and the occurrence of forced vibrations leads to an increase in roughness and waviness, as well as to the appearance of deviations of the nominal surface shape.

2. We used a fund of heuristic techniques to develop technological solutions to eliminate the identified potential failures at the design stage of the process.

3. The model of the adjustment process includes additional conditions that allow selecting the processing modes of discontinuous surfaces while ensuring the specified technical requirements, as well as verifying the correctness of technological decisions.

4. On the basis of the additional conditions obtained, we propose to use an algorithm for selecting the modes of machining of holes with intermittent surfaces by boring.

\section{References}

1. N. I. Tashlitskiy, Vestnik mashinostroyeniya, 4, 67 (1969)

2. G.S. Andreev, Vestnik mashinostroyeniya, 12, 48 (1978)

3. T. N. Loladze, Prochnost' $i$ iznosostoykost' rezhushchego instrumenta, (Mashinostroyeniye, Moscow, 320, 1982)

4. Y. G. Kabaldin, Stanki i instrument, 4, 27 (1980)

5. M.M. Simonyan, Vestnik mashinostroyeniya, 12, 54 (2004) 
6. E. A. Kudryashov, A. M. Nikonov, V. S. Rogovskii, A. V. Stetsurin, Russian Engineering Research, 29:2, 210 (2009)

7. E.A. Kudryashov, I.S. Krylov, N.A. Khizhnyak, Izvestiya yugo-zapadnogo gosudarstvennogo universiteta, 1:76, 34 (2018)

8. E.V. Pavlov, Stabilizatsiya protsessov chistovoy lezviynoy obrabotki preryvistykh poverkhnostey sinteticheskimi instrumental'nymi materialami. (ZAO "Universitetskaya kniga", Kursk, 153, 2018)

9. E.V. Pavlov, Izvestiya volgogradskogo gosudarstvennogo tekhnicheskogo universiteta, 9:204, 58 (2017)

10. A.E. Diniz, D.M. Gomes. A. Braghini, J. Mater Process. Technol., 159, 240 (2005)

11. D. Carou, E.M. Rubio, J.P. Davim, Reviews on Advanced Materials Science, 38:2, 110 (2014)

12. C. Venture, J. Kohler, B. Denkena, Journal of Manufacturing Processes, 19, 129 (2015)

13. X. Cui, J. Guo, J. Zheng, Mat. Des., 92:15, 424 (2016)

14. A.I. Polovinkin, Osnovy inzhenernogo tvorchestva, (Mashinostroyeniye, Moscow, 360, 1988)

15. I.A. Birger, R.R. Mavlyutov, Soprotivleniye materialov, (Nauka, Moscow, 560, 1986)

16. G.I. Granovskiy, V.G. Granovskiy, Rezaniye metallov, (Vysshaya shkola, Moscow, 304 (1985)

17. M.M. Matalin, Tekhnologiya mashinostroyeniya, (Lan', Moscow, 511, 2010) 